\title{
PEMBUATAN SEDIAAN LULUR SERBUK TRADISIONAL BIJI PEPAYA (Carica papaya L) DAN PATI KEDELAI (Glycine max L) UNTUK MENGATASI KULIT KERING
}

\author{
Tiya Nurmala1, Reti Puji Handayani2*, Farhan Jamani ${ }^{3}$ \\ 1,2,3 Sekolah Tinggi Ilmu Kesehatan Holistik \\ *Korespondensi: Jl. Veteran No. 272 Ciseureuh Purwakarta, Email: dewiratnasari@stikesholistic.ac.id
}

\begin{abstract}
ABSTRAK
Latar Belakang: Setiap orang pernah menderita kekeringan kulit, gatal, bersisik dan kemerahan karena berbagai macam penyebab. Kulit kering atau Xerosis cutis merupakan kelainan kulit dimana kulit menjadi kasar, bersisik, berkeriput dan kurang elastis dibandingkan kulit normal dan kering pada perabaan. Prevalensi xerosis di Indonesia adalah 50\%-80\% sedangkan pada beberapa negara lain seperti Brazil, Australia, Turki, dan lain-lain adalah 35\%-70\%. Merawat kulit secara teratur dapat dilakukan menggunakan lulur tradisional dari bahan alam. Penggunaan biji pepaya pada umumnya hanya dibuang atau di tanam atau dimanfaatkan sebagai bibit untuk dibudidayakan, padahal sebenarnya biji pepaya bisa diolah menjadi suatu sediaan yang bermanfaat. Biji pepaya kaya akan manfaat untuk kulit. Selain itu perawatan kulit kering juga dapat dilakukan dengan menggunakan kacang kedelai dan minyak zaitun.

Tujuan: Membuat dan menguji stabilitas sediaan secara organoleptis dan $\mathrm{pH}$ pada sediaan lulur serbuk tradisional untuk mengatasi kulit kering dari biji pepaya (Carica papaya $L$ ) dan pati kedelai (Glycine max L) dengan minyak zaitun sebagai penambah aroma.

Metode:Desain penelitian ini adalah penelitian tindakan atau action research dengan instrumen lembar pengamatan. Pengujian stabilitas sediaan lulur serbuk tradisional dilakukan selama 3 minggu pada suhu sejuk $10^{\circ} \mathrm{C}$ dan suhu kamar $25^{\circ} \mathrm{C}$.

Hasil: Menunjukkan bahwa sediaan lulur serbuk tradisional biji pepaya dan pati kedelai yang disimpan pada suhu sejuk $10^{\circ} \mathrm{C}$ memiliki stabilitas organoleptik bentuk, bau, warna serta tidak adanya jamur dan memiliki $\mathrm{pH}$ yang lebih baik dibandingkan dengan penyimpanan pada suhu kamar $25^{\circ} \mathrm{C}$.
\end{abstract}

Simpulan: Dari penelitian ini memberikan hasil dan stabilitas yang baik selama 3 minggu. Diharapkan penelitian selanjutnya dapat melakukan pengujian lain selain uji organoleptis dan $\mathrm{pH}$ dengan bentuk sediaan yang berbeda dari bahan biji pepaya dan kacang kedelai.

Kata kunci: Biji pepaya (Carica papaya L), pati kedelai (Glycine max L), stabilitas, sediaan lulur serbuk tradisional

\footnotetext{
ABSTRACT

Background: Everyone has suffered from skin dryness, itching, scaling and redness due to various causes. Xerosis cutis dry skin or a skin disorder where the skin becomes rough, scaly, wrinkled and less elastic than normal and dry skin on palpation. The prevalence of xerosis in Indonesia is 50\% 80\%, while in some other countries such as Brazil, Australia, Turkey, and others are 35\% -70\%. Caring for the skin on a regular basis can be done using traditional scrubs from natural materials. The use of papaya seeds usually just thrown or planted or used as seed for cultivation, when in fact the papaya seeds can be processed into a useful preparation. Papaya seeds rich in benefits for the skin. In addition to dry skin treatment can also be done using soy beans and olive oil.

objective: Create and test the stability of the preparation is organoleptic and $p H$ in the preparation of traditional herbal powders for dry skin from the seeds of papaya (Carica papaya L) and starch soybean (Glycine max L) with olive oil as an aroma enhancer.

Methods: This study was action research or action research with the observation sheet instruments. Testing the stability of traditional powder herbal preparation made for 3 weeks at cool temperature of $100 \mathrm{C}$ and $250 \mathrm{C}$ room temperature.

Result: Indicates that the preparation of traditional herbal papaya seed powder and soy starch stored at a cool temperature of $100 \mathrm{C}$ has the organoleptic stability of shape, smell, color and absence of fungi and have a $\mathrm{pH}$ that is better than the room temperature storage at $250 \mathrm{C}$.
} 
Conclusion: This study provides results and good stability for 3 weeks. It is expected that further research can do the testing other than organoleptic test and $\mathrm{pH}$ with different dosage forms of the ingredients of papaya seeds and soybeans.

Keywords: Body scrub powder traditional, papaya Seed (Carica papaya L), stability, starch soybean (Glycine max L)

\section{PENDAHULUAN}

Setiap hari jutaan orang menderita kekeringan kulit, gatal, bersisik dan kemerahan karena berbagai macam penyebab ${ }^{14}$. Kulit kering atau Xerosis cutis merupakan kelainan kulit dimana kulit menjadi kasar, bersisik, berkeriput dan kurang elastis dibandingkan kulit normal dan kering pada perabaan ${ }^{3}$. Prevalensi xerosis di Indonesia adalah 50\%-80\% sedangkan pada beberapa negara lain seperti Brazil, Australia, Turki, dan lain lain adalah 35\%-70\% ${ }^{12}$.

Merawat kulit secara teratur merupakan langkah awal untuk menambah dan menjaga kecantikan kulit secara alami. Salah satu cara untuk merawat kulit kering secara alami yaitu menggunakan lulur tradisional. Lulur tradisional merupakan salah satu sediaan kosmetik yang berbahan dasar alami segar atau bahan yang sudah dikeringkan dari tanaman dan buah ${ }^{6}$. Produk luluran yang beredar di pasaran umumnya mengandung bahan tambahan kombinasi seperti bahan mineral/sintetis. Pada penelitian [11] pembuatan sediaan lulur krim tipe M/A ekstrak biji kedelai dibuat dengan menambahkan emulgator asam stearat dan bahan pengental setil alkohol².

Dengan memanfaatkan bahan yang ada di sekitar, lulur juga dapat dibuat dari bahan alam. Biji pepaya merupakan bagian dari buah pepaya yang tidak dimakan. Penggunaan biji pepaya pada umumnya hanya dibuang atau di tanam atau dimanfaatkan sebagai bibit untuk dibudidayakan, padahal sebenarnya biji pepaya bisa diolah menjadi suatu sediaan yang bermanfaat ${ }^{1}$. Biji pepaya kaya akan manfaat untuk kulit. Biji pepaya mengandung enzim papain yang dapat mencegah keriput, mengecilkan pori-pori kulit, dan melembabkan kulit ${ }^{13}$. Penelitian sebelumnya dilakukan dengan membuat sediaan lulur tradisional biji pepaya dan pati bengkuang untuk mengatasi kulit kering, dalam hal ini peneliti membuat sediaan lain dalam bentuk lulur serbuk tradisional dengan penambahan pati kedelai. Perawatan kulit kering juga dapat dilakukan dengan menggunakan kacang kedelai. Kacang kedelai mengandung vitamin E yang mampu menyingkirkan sel kulit mati dan membentuk sel kulit baru, serta melembabkan kulit ${ }^{15}$. Selain itu, minyak zaitun juga dapat digunakan sebagai penambah aroma karena aroma yang enak dan segar serta memberi efek relaksasi ${ }^{10}$. Oleh karena itu, peneliti memilih biji pepaya (Carica papaya L) dan pati kedelai (Glycine max $L$ ) sebagai bahan lulur serbuk tradisional dengan penambahan minyak zaitun sebagai penambah aroma yang mempunyai kandungan baik untuk kulit yang dapat melembabkan serta mengangkat sel kulit mati untuk kulit kering.

\section{METODE PENELITIAN}

Penelitian ini dilaksanakan di Laboratorium STIKes Holistik Purwakarta yang berada di Jl.Veteran No.272 Ciseureuh Purwakarta pada bulan Mei sampai Agustus 2019. Dalam penelitian ini sediaan yang akan dibuat dan diteliti 
adalah lulur serbuk tradisional yang berasal dari biji pepaya (carica papaya $L$ ) dan pati kedelai (Glycine max L). Desain penelitian yang digunakan adalah penelitian tindakan.

Biji pepaya dan kacang kedelai sebagai bahan baku pembuatan sediaan lulur serbuk tradisional diperoleh langsung dari Pasar Wanayasa RT 12/RW 05, Desa Wanayasa, Purwakarta. Kacang kedelai yang digunakan adalah kacang kedelai kuning sedangkan, biji pepaya yang digunakan yaitu biji pepaya yang memiliki warna coklat kehitaman, tidak berbau, tidak berasa, serta berbentuk agak bulat ${ }^{8}$.

Tabel 3.1 Tabel Susut Pengeringan Serbuk Biji Pepaya

\begin{tabular}{|c|c|c|c|c|c|c|c|}
\hline Sampel & Berat & Cawan & Cawan+ & \multicolumn{3}{|c|}{ Penimbangan } & \multirow{2}{*}{ Hasil } \\
\cline { 5 - 7 } & Sampel & Kosong & Sampel & Ke-1 & Ke-2 & Ke-3 & \\
\hline A & $5 \mathrm{gr}$ & $52,35 \mathrm{gr}$ & $57,35 \mathrm{gr}$ & $57,11 \mathrm{gr}$ & $57,10 \mathrm{gr}$ & $57,09 \mathrm{gr}$ & $5,2 \%$ \\
\hline B & $5 \mathrm{gr}$ & $40,02 \mathrm{gr}$ & $45,02 \mathrm{gr}$ & $44,47 \mathrm{gr}$ & $44,46 \mathrm{gr}$ & $44,46 \mathrm{gr}$ & $5,2 \%$ \\
\hline C & $5 \mathrm{gr}$ & $48,72 \mathrm{gr}$ & $53,72 \mathrm{gr}$ & $53,47 \mathrm{gr}$ & $53,47 \mathrm{gr}$ & $53,46 \mathrm{gr}$ & $5,2 \%$ \\
\hline \multicolumn{7}{|c|}{ Rata - rata } & $5,2 \%$ \\
\hline
\end{tabular}

Tabel 3.2 Tabel Susut Pengeringan Pati Kedelai

\begin{tabular}{|c|c|c|c|c|c|c|c|}
\hline Sampel & Berat & Cawan & Cawan+ & \multicolumn{3}{|c|}{ Penimbangan } & \multirow{2}{*}{ Hasil } \\
\cline { 5 - 7 } & Sampel & Kosong & Sampel & Ke-1 & Ke-2 & Ke-3 & \\
\hline A & $5 \mathrm{gr}$ & $50,58 \mathrm{gr}$ & $55,58 \mathrm{gr}$ & $55,34 \mathrm{gr}$ & $55,31 \mathrm{gr}$ & $55,30 \mathrm{gr}$ & $5,6 \%$ \\
\hline B & $5 \mathrm{gr}$ & $49,86 \mathrm{gr}$ & $54,86 \mathrm{gr}$ & $54,60 \mathrm{gr}$ & $54,59 \mathrm{gr}$ & $54,59 \mathrm{gr}$ & $5,4 \%$ \\
\hline C & $5 \mathrm{gr}$ & $52,16 \mathrm{gr}$ & $57,16 \mathrm{gr}$ & $56,92 \mathrm{gr}$ & $56,90 \mathrm{gr}$ & $56,89 \mathrm{gr}$ & $5,4 \%$ \\
\hline \multicolumn{7}{|c|}{ Rata - rata } & $5,5 \%$ \\
\hline
\end{tabular}

Tabel 3.3 Pengamatan Uji pH Selama 3 Minggu

\begin{tabular}{|c|c|c|c|c|}
\hline \multirow{2}{*}{ Sampel } & \multicolumn{2}{|c|}{ Suhu Ruang $\mathbf{2 5}^{\mathbf{0}} \mathbf{C}$} & \multicolumn{2}{c|}{ Suhu Sejuk $\mathbf{1 0}^{\circ} \mathbf{C}$} \\
\cline { 2 - 5 } & Hari ke-1 & Hari ke-21 & Hari ke-1 & Hari ke-21 \\
\hline $\mathbf{1}$ & 5,1 & 5,4 & 5,1 & 5,1 \\
\hline $\mathbf{2}$ & 5,1 & 5,5 & 5,1 & 5,1 \\
\hline $\mathbf{3}$ & 5,1 & 5,4 & 5,1 & 5,1 \\
\hline $\mathbf{4}$ & 5,1 & 5,4 & 5,1 & 5,1 \\
\hline $\mathbf{5}$ & 5,1 & 5,5 & 5,1 & 5,1 \\
\hline
\end{tabular}

Bahan yang diperlukan dalam membuat sediaan lulur serbuk tradisional ini yaitu biji pepaya, kacang kedelai dan minyak zaitun untuk menghilangkan bau dari pati kedelai. Biji pepaya (Carica papaya $L$ ) dan kacang kedelai (Glycine $\max L$ ) sebagai bahan baku pembuatan sediaan lulur serbuk tradisional diperoleh langsung dari Pasar Wanayasa RT 12/RW 05, Desa Wanayasa, Purwakarta. Minyak zaitun (Olea europaea) yang digunakan yaitu minyak 
zaitun yang berkhasiat sebagai penambah aroma yang dibeli di Toko/Warung.

Bahan baku biji pepaya sebanyak 200 gram dan kacang kedelai sebanyak 500 gram dilakukan proses sortasi bertujuan untuk memisahkan biji pepaya dan kacang kedelai yang dapat digunakan untuk proses selanjutnya dengan yang tidak layak digunakan. Biji pepaya dan kacang kedelai kemudian dicuci secara terpisah yang bertujuan untuk membersihkan sisa-sisa bahan organik asing yang masih menempel. Rebus kacang kedelai yang sudah di cuci bertujuan untuk mematangkan kacang kedelai sampai kulit kacang terlepas. Proses perebusan dilakukan dengan memanaskan kacang kedelai dengan air pada suhu $100^{\circ} \mathrm{C}$ selama 10 menit. Kemudian biji pepaya dan kacang kedelai dibuat simplisia dengan cara dikeringkan dengan menggunakan oven. Biji pepaya dikeringkan menggunakan oven pada suhu $80^{\circ} \mathrm{C}$ selama 6 jam sedangkan, kacang kedelai dikeringkan menggunakan oven pada suhu $60^{\circ} \mathrm{C}$ selama 6 jam. Pengeringan ini bertujuan untuk meningkatkan daya tahan simplisia sehingga dapat disimpan dalam waktu yang lama. Biji pepaya dan kacang kedelai kering kemudian di blender dan di ayak menggunakan saringan kecil. Proses pengayakan bertujuan untuk memperoleh serbuk biji pepaya dan pati kedelai dengan ukuran seragam dan halus.

Setelah dikeringkan diperoleh simplisia serbuk biji pepaya sebanyak 190,71 gram dan pati kedelai sebanyak 401,15 gram. Kemudian dilakukan susut pengeringan simplisia serbuk biji pepaya dan pati kedelai. Pada Tabel 3.1 hasil susut pengeringan simplisia serbuk biji pepaya dengan metode pengovenan sangat stabil karena ketiga sampel mempunyai susut pengeringan rata-rata 5,2\%. Pada Tabel 3.2 hasil susut pengeringan simplisia pati kedelai dengan metode pengovenan sangat stabil karena ketiga sampel mempunyai susut pengeringan rata-rata $5,5 \%$ sehingga memenuhi persyaratan susut pengeringan yang tidak boleh $>10 \% 4$.

Pembuatan sediaan lulur serbuk tradisional serbuk biji pepaya (Carica papaya $L$ ) dan pati kedelai (Glycine max $L$ ) dicampur dengan perbandingan 1: 3 [7] dengan berat total sediaan 50 gram terdiri dari 12,5 gram serbuk biji pepaya dan 37,5 gram pati kedelai. Pada saat preformulasi, peneliti mencoba membuat sediaan tanpa penambahan bahan lain hasilnya sediaan menjadi bau kemudian di tambahkan $15 \mathrm{ml}$ minyak zaitun sebagai penambah aroma untuk menghilangkan bau dari pati kedelai ${ }^{9}$, lalu dimasukkan kedalam wadah tertutup rapat.

Pengujian stabilitas fisik sediaan selama tiga minggu merupakan tahap selanjutnya. Sediaan lulur serbuk tradisional biji pepaya dan pati kedelai dibuat masingmasing sebanyak 5 (lima) sampel beratnya masing-masing sebanyak 5 gram. Disimpan pada suhu yang berbeda 5 (lima) sampel pada suhu ruang $25^{\circ} \mathrm{C}$ dan 5 (lima) sampel pada suhu sejuk $10^{\circ} \mathrm{C}$. Kemudian sediaan lulur serbuk tradisional dilakukan uji organoleptis yang dilakukan selama tiga minggu dan diamati setiap 3 hari sekali untuk memastikan ada atau tidaknya perubahan bentuk, warna ,bau maupun tumbuhnya jamur. Selain itu, dilakukan uji pH pada hari ke -1 dan hari ke -21 untuk mengetahui sama tidaknya $\mathrm{pH}$ sediaan dengan $\mathrm{pH}$ kulit tubuh.

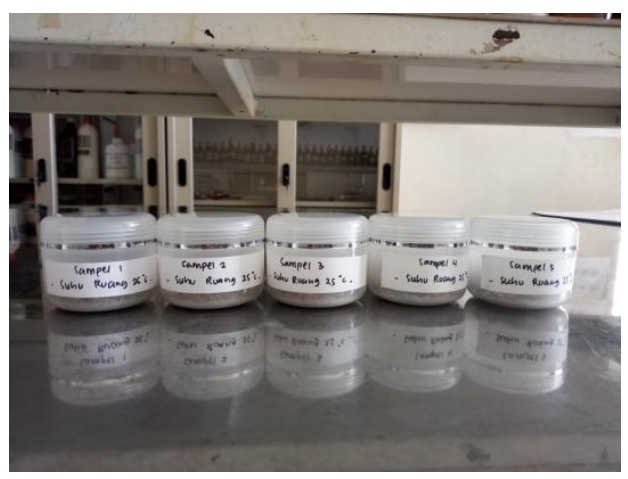

Gambar 3.1 Sampel Suhu Ruang 25ㄷ 


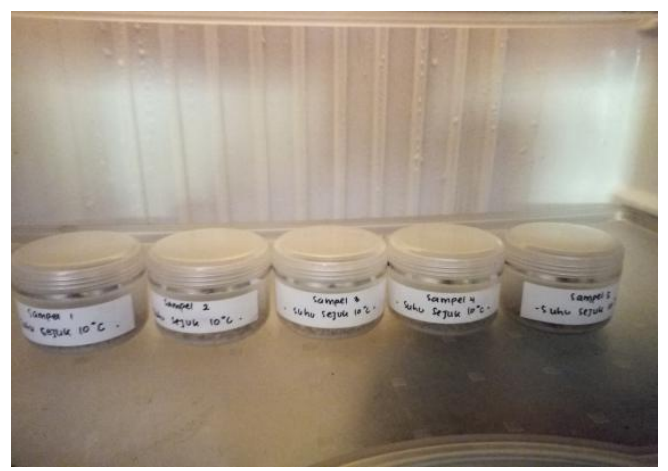

Gambar 3.2 Sampel Suhu Sejuk $10^{\circ} \mathrm{C}$

Berdasarkan Tabel 3.3 hasil pengujian organoleptis sediaan yang meliputi bentuk, warna, bau, ada tidaknya jamur pada sediaan selama 3 minggu yang disimpan pada suhu ruang $25^{\circ} \mathrm{C}$ dan suhu sejuk $10^{\circ} \mathrm{C}$. Pada suhu ruang dan suhu sejuk bentuk sediaan lulur serbuk tradisional biji pepaya (Carica papaya $L$ ) dan pati kedelai (Glycine max $L$ ) serbuk kasar, warna hitam kekuningan, serta tidak adanya jamur pada sediaan. Akan tetapi, pada pengamatan bau sediaan yang disimpan pada suhu ruang berubah pada hari ke-9 sampai hari ke-21 bau khas minyak zaitun melemah. Sedangkan, bau sediaan yang di simpan pada suhu sejuk tetap stabil dari hari ke-1 sampai hari ke-21 yaitu bau khas minyak zaitun.

Pada Tabel 3.3 hasil pengujian $\mathrm{pH}$ sediaan yang di simpan pada suhu sejuk masih stabil dari hari ke-1 sampai hari ke-21 yaitu 5,1. sedangkan, $\mathrm{pH}$ sediaan yang disimpan pada suhu ruang berubah yaitu pada hari ke-1 pH nya 5,1 dan pada hari ke21 sampel 1,3 dan $4 \mathrm{pH}$ nya 5,4 tetapi sampel 4 dan 5 pH nya 5,5. pH normal kulit manusia berkisar antara 4,5-6,5 [5] sehingga sediaan aman untuk digunakan.

\section{SIMPULAN}

Berdasarkan hasil penelitian, pembuatan sediaan lulur serbuk tradisional biji pepaya (Carica papaya $L$ ) dan pati kedelai (Glycine $\max L$ ) dibuat dengan mencampur serbuk biji pepaya dan pati kedelai dengan perbandingan 1:3 dengan menambahkan minyak zaitun sebagai penambah aroma untuk menghilangkan bau dari pati kedelai. Sediaan lulur serbuk tradisional biji pepaya (Carica papaya $L$ ) dan pati kedelai (Glycine max $L$ ) stabil dan tidak berubah secara signifikan dilihat dari uji stabilitas secara organoleptis dan $\mathrm{pH}$ sediaan selama tiga minggu. Sediaan yang paling baik dan stabil yaitu sediaan yang di simpan pada suhu sejuk $10^{\circ} \mathrm{C}$ dengan uji organoleptis dan uji $\mathrm{pH}$ selama tiga minggu lebih baik dibandingkan sediaan yang disimpan pada suhu ruang $25^{\circ} \mathrm{C}$. Hasil uji organoleptis sediaan yang disimpan pada suhu sejuk $10^{\circ} \mathrm{C}$ yaitu bentuk sediaan serbuk kasar, warna hitam kekuningan, bau khas minyak zaitun, dan $\mathrm{pH}$ sediaan 5,1 .

Penelitian ini hanya menguji stabilitas sediaan lulur serbuk tradisional biji pepaya (Carica papaya $L$ ) dan pati kedelai (Glycine $\max L$ ) secara organoleptis dan $\mathrm{pH}$ dengan cara penyimpanan yang berbeda, diharapkan penelitian selanjutnya dapat melakukan pengujian lain selain uji organoleptis dan $\mathrm{pH}$ dengan bentuk sediaan yang berbeda dari bahan biji pepaya dan kacang kedelai. Serta, dapat menambah proporsi formulasi minyak zaitun dengan jumlah tertentu untuk menjaga kelembaban pada sediaan.

\section{DAFTAR PUSTAKA}

1. Aniatul Hidayah, 2011. Herbal Kecantikan. Yogyakarta. Penerbit : Citra Media.

2. Ansel, H.C., 2005. Pengantar Bentuk Sediaan Farmasi. Edisi Keempat, Penerjemah: Farida Ibrahim, Penerbit UI Press, Jakarta.

3. Demis DJ. Dry Skin. In : Clinical Dermatology. 14th ed. Philadelpia : Harper\&Row. 1987. p. 1-3. 
4. Depkes RI, 1989. Materia Medika Indonesia. Jilid V. Jakarta: Departemen Kesehatan Republik Indonesia. Halaman 179.

5. Draelos, Z. D., dan Lauren A. Thaman, 2006. Cosmetic Formulation Of skin Care Product, 362, Taylor and Francis Group, New York.

6. Fauzi, Ridwan, Aceng, Nurmalina, Rina (2012). Merawat Kulit dan Wajah Jakarta : PT Elex Media Komputindo.

7. Fury Indah Meliani, 2016. Pemanfaatan Biji Pepaya (Carica papaya L) dan Pati Bengkuang (Pachyrhizus Erosus) sebagai Lulur Tradisional untuk Kulit Kering. Skripsi, Universitas Negeri Semarang.

8. Kalie, M.B, 1996. Bertanam Pepaya. Edisi Revisi. Jakarta : Penerbit Swadaya.

9. Nela, 2011. Pengaruh Konsentrasi Tepung Beras Terhadap Daya Angkat Sel Kulit Mati dan Sifat Fisik Lulur Bedak Dingin. Jurnal Fakultas Farmasi, Universitas Ahmad Dahlan : Yogyakarta.

10. Nining Riana Sari, Erna Setyowati. (2014). Pengaruh Masker Jagung dan Minyak Zaitun Terhadap Perawatan Kulit Wajah. Jurnal : Fakultas Teknik, Universitas Negeri Semarang.
11. Nunik Kurniasih, 2016. Formulasi Sediaan Krim Tipe M/A Ekstrak Biji Kedelai (Glycine max L) : Uji Stabilitas Fisik dan Efek Pada Kulit. Jurnal Farmasi : Universitas Muhammadiyah Surakarta.

12. Paul C, Maumus-Robert S, MazereeuwHautier J, Guyen C, Saudez X SA. Prevalence and risk factors for xerosis in the elderly : a cross - sectional epidemiological study in primary care. JAAD [Internet]. 2011 [cited 2016 Feb 4];5(3):223-60.

13. Setiabudi.H, 2014. Aktivitas Antibakteri Ekstrak Biji Pepaya (Carica papaya L) terhadap Escherichia coli dan Streptococcus pyogenes. Jurnal Pertanian Fakultas Teknobiologi, Universitas Atma Jaya Yogyakarta.

14. Simion FA, Abrutyn ES, Draelos ZD (2005). Ability of moisturizers to reduce dry skin and irritation and to prevent their return. J Cosmet Sci [Internet].

15. Wulan Joe, 2012. Pengaruh Konsentrasi Putih Telur dan Suhu Pengeringan Terhadap Karakterisik Tepung Air Rebusan Kacang Kedelai (Glycine max L.) dengan Metode Foam Mat Drying. Jurnal Fakultas Teknik, Universitas Pasundan Bandung. 